\title{
IoT recycle management system to support green city initiatives
}

\author{
Ruwaida Ramly ${ }^{1}$, Aznida Abu Bakar Sajak ${ }^{2}$, Muhaira Rashid ${ }^{3}$ \\ ${ }^{1,3}$ Department of Computer Engineering, MIIT, Universiti Kuala Lumpur, Malaysia \\ ${ }^{2}$ Department of System and Networking, MIIT, Universiti Kuala Lumpur, Malaysia
}

\begin{tabular}{l} 
Article Info \\
\hline Article history: \\
Received Oct 1, 2018 \\
Revised Jan 8, 2019 \\
Accepted Feb 21, 2019 \\
\hline
\end{tabular}

\section{Keywords:}

Arduino

Green technology policy

IoT

Rebate

Recycle

\begin{abstract}
In July 2009, Government of Malaysia had launched Green Technology Policy as new initiatives from Malaysia to handle greenhouse effect issue and energy usage through application and green technologies development to reduce carbon footprint. This project, Internet of Things (IoT) Recycle Management System is an idea to help the government in gearing the nation towards this aim with a developed system or technology that support green environment. For this paper, the intended cities are Putrajaya and Cyberjaya areas since both of these cities are chosen as a pioneer for the Green City Initiatives by the Government. This Arduino based Internet of Things (IoT) project is an upcoming urban technology that transforms everyday current recycling system into an ecosystem that would enrich our lives and make it exciting to recycle things anywhere. Hence, encourages Malaysian to recycle their things regularly and make it as a normal routine. This project consists of the development of recycle waste bin that have sensor-based and a database with webpage system for client interface which be connected via Internet network. This project has a huge prospect to be implemented in the future, should there be a collaboration with Government entities and NonGovernment entities as this effort needs huge support from all Malaysians in order to realize first class mentality transformation.
\end{abstract}

Copyright $\odot 2019$ Institute of Advanced Engineering and Science. All rights reserved.

\section{Corresponding Author:}

Ruwaida Ramly,

Department of Computer Engineering,

Malaysian Institute of Information Technology,

1016 Universiti Kuala Lumpur,

Jalan Sultan Ismail, 50250, Kuala Lumpur, Malaysia

Email: ruwaida@unikl.edu.my

\section{INTRODUCTION}

Green initiatives refer to a friendly relationship between humans and their habitat. It is an act of living by focusing on not creating harm to environment, and to prevent as much harm from occurring to the environment through interactions with it. Any activities that promote green living that help to conserve energy and also prevent air, water and noise pollution are considered as eco green activities.

Led by the government, non-profit organizations or small independent eco green groups, cities everywhere are bursting with an array of ideas on how to decrease waste and make recycling initiatives more appealing to local residents. San Francisco in June 2009 implemented nation's first mandatory composting law where the new law has seen demand for the composting containers, with city waste collection companies delivering over 100 per day. It is hoped that the law could push the city to eliminate all landfill waste by 2020 [1].

Toilet-to-tap water systems are still a taboo to most countries, but a water park in the western German state of North Rhine-Westphalia showcases the water treatment process through colorful architecture and a great set of eco-features. The design uses a constructed wetlands and a rainwater-harvesting roof to clean the liquid. An on-site community garden also gets its drink from the treatment park [2]. 
While in Argentina, designer from Argentine studio, Designo Patagonia created a series of Tetrisshaped street furniture that showcases recyclable materials like plastic bottles, cans, and paper. Located within a city park in Córdoba, these unique seats and tables were designed for recreation and to teach passerby about sustainability issues. The Tetris-shaped containers are made from iron frames and glass, are packed with recyclable materials, and feature easy-to-understand eco-facts written on the surface of each piece [3].

Several initiatives have been implemented as in [4], as well as ongoing efforts being undertaken since the beginning of the development of Putrajaya, Malaysia. The scopes include city planning, administration and management, integrating nature in community development, energy and water usage, transport and mobility, and waste management. It is reported that solid waste sector is the second largest sector that contributed to the percentage of greenhouse gases (GHG) in Malaysia after the energy sector [4]. Hence, this project is focused on the development of prototype model of waste smart bin.

One of the main concepts of IoT is to make it as efficient as possible for users to control devices as per their usage and save resources. When it comes to the waste industry, waste and recycling collectors are always looking at ways to minimize cost and increase productivity when possible [5-12]. An integration of IoT is introduced in this system to connect and exchange data in forms of measuring the weight of recycle waste thus collecting them accordingly and determining the amount of rebate points.

This prototype model consists of recycle bin, load cell that acts as a weight sensor, Arduino board module as a controller, RFID module to identify the user, Ethernet shield and a server, and LCD to display the weight of the recycle waste and the rebate points. The server stores the users' information based on the RFID tag and updates the weight of recycle waste together with the rebate points. These data will also be displayed on the Webpage for users' reference. Rebate points accumulated will be the rewards for the users to encourage them to recycle their waste continuously, and it is hoped that the next improvement can be done where these rebate points can be used as part of tax exemption for Malaysian as to appreciate their support towards Green City initiatives.

\section{RELATED WORK}

\subsection{Multipurpose Garbage Monitoring System using IoT by B. Shaikh}

Here in [13], the researcher has figured out a new model for the municipal dustbins which indicates the center of municipality for immediate cleaning of dustbins. The dustbin is also designed to compress the garbage periodically thus preventing the unnecessary occupying of dustbin's space by light weighted but space occupying garbage particles like sponges. A leaf switch is pressed by the garbage when it reaches a particular level and an Arduino Uno is programmed in such a way that when the garbage reaches this particular level, intimation is given to the central hub through IoT-based.

An efficient method to monitor the waste has been designed with some sensors and the output will be displayed on the monitoring screen of municipality office. Level sensor is utilized to detect the level of the garbage inside the bin and the LDR is used to minimize the wastage of electricity. A temperature sensor placed at the garbage bin is used to detect the air pollution as well as temperature around the bin. IoT is implemented in this project so that the input and output can always be accessed and monitored from anywhere.

In this paper, waste management issues have been solved by smart bin, interfaced by GSM and ultrasonic sensor with the help of microcontroller based Arduino. This paper provides improved solution to replace traditional dustbin into smart bin.

This project uses microcontroller ATMEGA 16 and certain sensors like PIR sensor, Hall Effect sensor, solar sensor and LDR sensor that are connected to the microcontroller through an interfacing circuit and an amplifier. The output could be viewed on LCD display, solar and LDR sensor sense the light and the presence of car or human will turn lights ON. This project is inspired by the efficiency of automatic street lighting system based on low cost microcontroller that controls the LED using light sensor, rain sensor and laser sensor.

\subsection{Smart Dustbins for Smart Cities by B. Singh and M. Kaur}

The system in [14] proposed an IT solution to garbage collection providing greater accessibility, planning appropriately for disposing process and at the same time enabling collection of garbage generation data.

This proposed system has been divided into three layers:

a. Dustbin Layer: consists of sensor and transducer interfaced by internet and Wi-Fi that enables communication between devices. Every dustbin contains a sensor which sense the level of waste and send fill up status of the dustbin to the server. It also sends its current GPS location to the server at 
regular intervals.

b. Server Layer: server collects the fill up status and location of dustbins. It processes the clients query and to respond with nearest dustbin location and exact direction to access dustbin.

c. Client Server: clients request for the nearest location of the IT enabled dustbin to the server using Mobile App designed for this purpose.

For this system, the garbage is collected optimally using four scheduling algorithm:

d. Fixed Scheduling: The collection process carried out on fixed interval basis, for example to be collected on every three days.

e. Priority Scheduling: The dustbins are collected according to the highest current fill up status. For example, 3 dustbins with fill up status of $92 \%, 80 \%$ and $96 \%$, the collection process will go for the $96 \%$ of fill up dustbin, followed by $92 \%$ and lastly the $80 \%$ fill up dustbin.

f. Average Threshold Scheduling: This schedule makes use of the average value of all fill up status of all dustbins. If average fill up is greater than some threshold, example $70 \%$, then the collection process will take effect according to the Priority scheduling.

g. Full Dustbin Capacity Utilization Scheduling: The collection process will only take place when all the dustbins are completely filled up.

2.3. IoT Based Smart Garbage System for Efficient Food Waste Management by Insung Hong, Sunghoi Park, Beomseok Lee, Haekeun Lee, Daebeom Jeong and Sehyun Park

This paper in [15] proposed an IoT-based smart garbage system composed of a number of smart garbage bins, routers and servers. Each bin plays a role in collecting food waste, and they are battery operated for mobility conveniences to residents, performs various techniques through wireless communication. The server collects and analyzes the status of all bins and residents information collected through RFID readers. The router is used for server load distribution.

This smart garbage system applies an adaptive user-oriented charge policy in function of charging fees per $\mathrm{kg}$ of food waste. The adaptive user-oriented charge policy goes like this: Charge fees is decreased when the food waste amount of particular month is reduced compared to the previous month.

This proposed system is divided into two domains, an administration domain and a service domain. Service domain identifies which residents throw away their food waste to their respective smart garbage bin, and these information will be collected and transferred to the administration domain. Administration domain will then analyze and process the information from the service domain.

The hardware structure is composed of load cell, main system, interface, modem, motor, LCD display, Analog-to-digital converter and RFID module.

\section{METHODOLOGY}

The chosen methodology is Structured Model. This model is chosen because the process flow is suitable with the development of this system. As shown in Figure 1, this method consists of four phases: planning, analysis, design and implementation. The orderly sequence of development phases are to ensure the sufficiency of documentation and design reviews that helps to increase the quality, reliability and maintainability of the developed project.

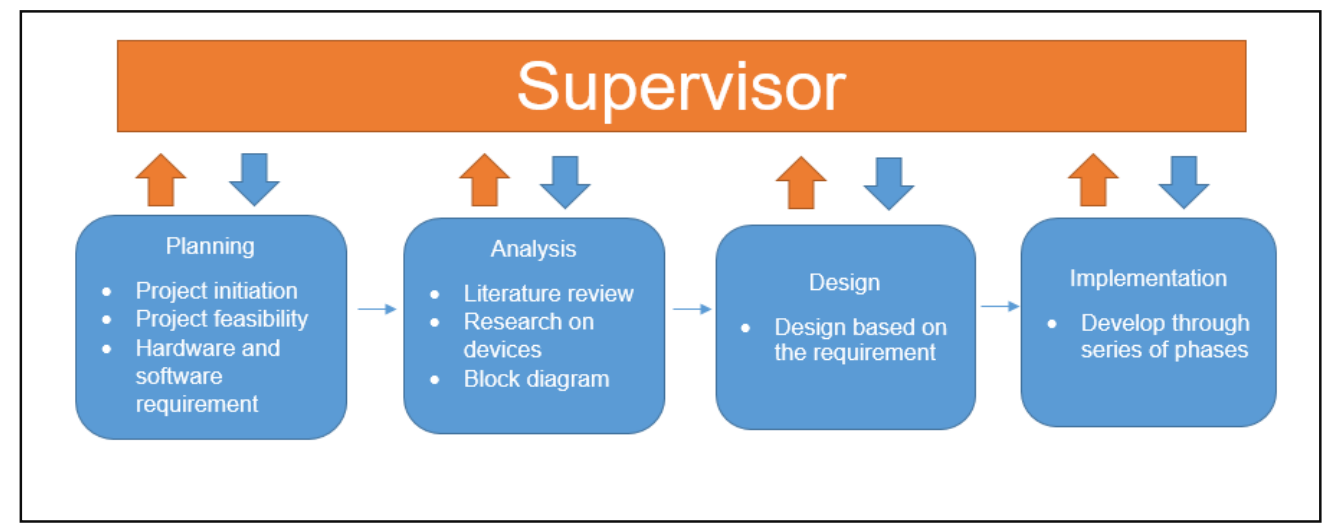

Figure 1. Structured Model 
Planning phase is where the project initiation took place by describing the objective(s) and the scope(s) of the project. The design and requirements for the project are identified and the cost estimation is prepared. It is vital to ensure that the project is feasible by studying the methods and resources available.

Analysis phase consists of investigation of current system via literature review, determining the systems options and refining the technical requirements that can be proceed with research on selected devices. The important part in this analysis phase is to understand the business or current needs and the process requirements of the new system. Research and analysis that related to development of this project were done through this phase.

Diagrammatic representation and other useful modeling techniques are needed in design phase in order to have better understanding of the project. Here, creating the logical and physical design are important as it reflects the specifications and requirements that have been defined in planning and analysis phase.

Implementation phase consists of development and installation of the hardware, software construction, data storage and retrieval. The integration of the hardware and software is then being prototyped and go through multiple test to obtain the expected results. The results are analyzed and discussed in this phase. Should there be any errors, the troubleshooting process will take place. The prototype will then be refined until accomplishment of the final product. Any improvement needed is based on the results and findings. Figure 2 shows the Block Diagram of this project.

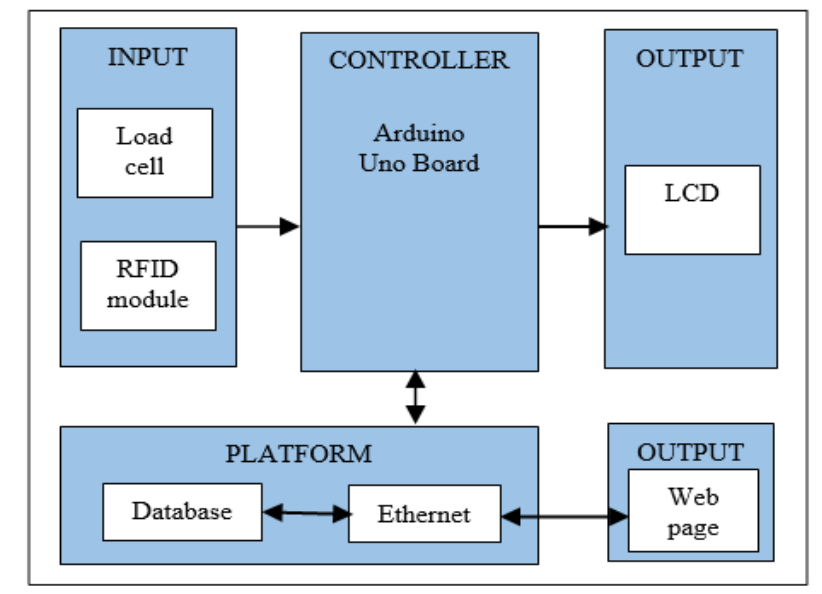

Figure 2. Block Diagram for IoT Recycle Management System

A load cell is a weight sensor that converts a load or force acting on it into an electronic signal, here is voltage signal that later will be amplified accordingly. If an object's weight changes over time, the load cell simply sense the presence of the objects by measuring the load applied to its surface bar. The load cell is placed in the recycle bin and is used to measure the weight of the recycle waste that being threw into the recycle bin. RFID (radio frequency identification) is a technique facilitating identification of any product or item without the requirement of any line of sight amid transponder and reader. RFID module used here consists of the tag and its reader, where the reader is used to scan the tag that represents the details of the user. The reason for choosing RFID as the data collection technology is mainly based on low price and the application environment. The low price enables the disposable feature of the tags and the RFID system can overcome the difficulties of barcode and/or written identification systems as it is less prone to contamination from the waste and/or weather conditions [16].

Controller used in this project is Arduino Uno, where it controls the inputs and outputs of the project. As for the output, the LCD is used to display in real-time the weight of the recycle waste and rebate points to the users.

To realize an IoT-based recycle management system [17-21], this project has also been interfaced to a Webpage as a platform for the users to check and update their total rebate points. The Webpage will also display the users' details based on the information acquired by the database. The database gets these data from the RFID reader and detection of the load cell. Ethernet is used as the platform to connect the Arduino with database and Webpage by using Internet network.

Flowchart shown in Figure 3 illustrates the whole process of this system where each process has gone through multiple test during the development of the prototype model. 


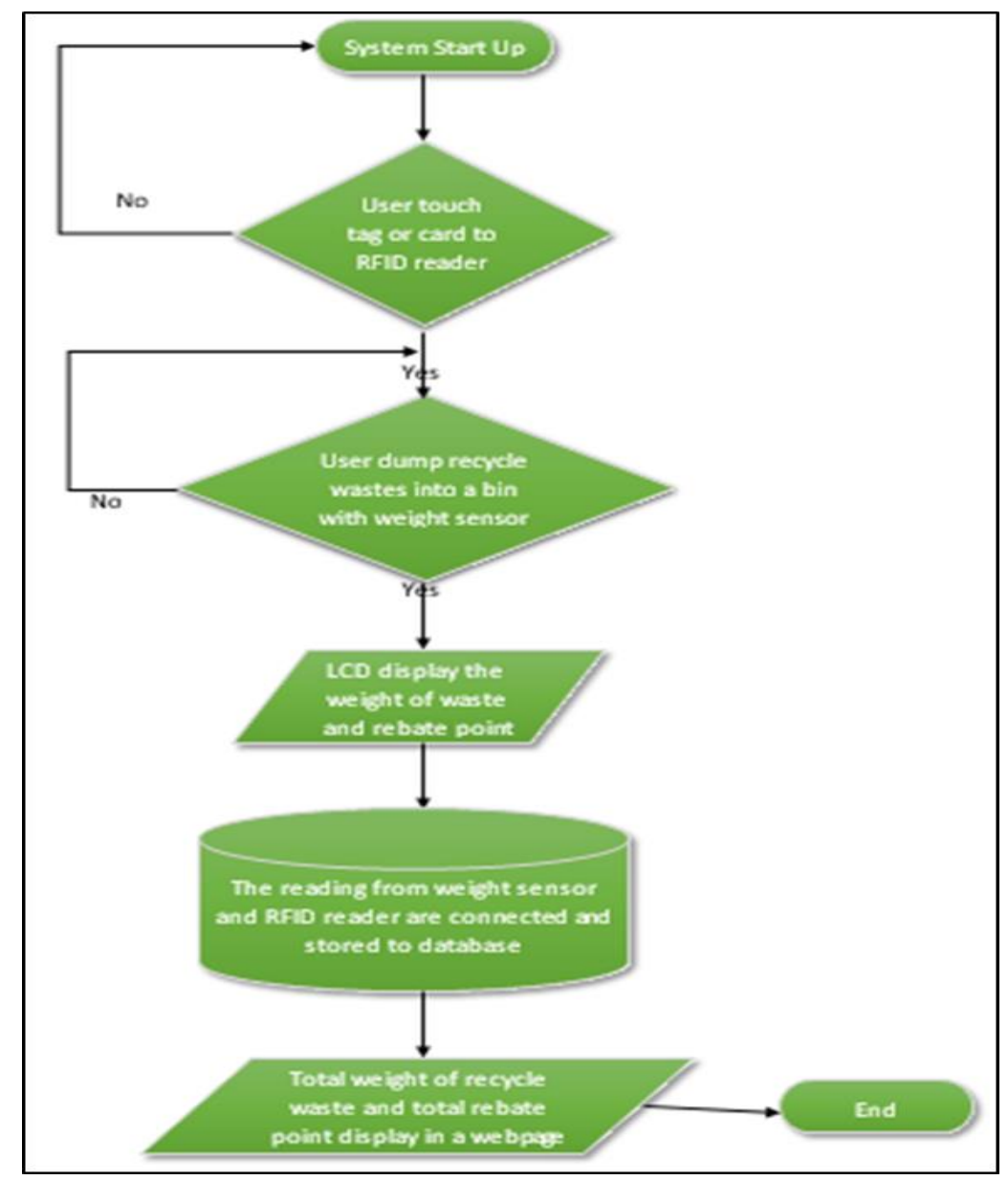

Figure 3. Flow Chart

Figure 4 shows the hardware used in developing the prototype model of the system. An Arduino board, a 16x2 LCD, 1kg load cell with HX711 amplifier, RFID reader with RFID tag/card and for the connectivity of the Arduino to the internet, the Ethernet Shield is used. In order to keep an intact pin layout, the Ethernet Shield is connected to the Arduino Board by stacking it on top of the Arduino Board.

Figure 5 and 6 show the getting started of the system. The system starts by displaying the system's title on the LCD, followed by the instructions to users. Users are requested to tap their unique RFID tag onto the RFID reader. Each user has their own unique RFID tag. Figure 7 represents a recycle waste dumped into a bin, waiting for the load cell to detect and weigh the recycle waste

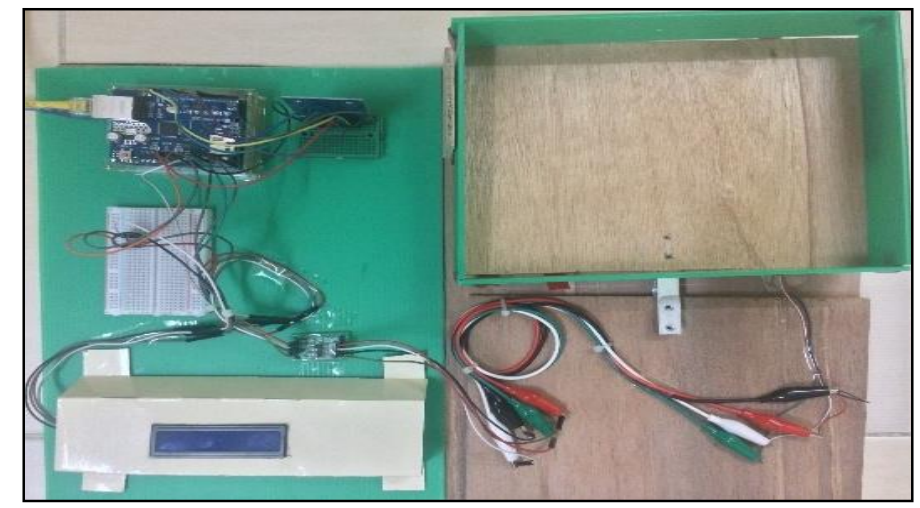

Figure 4. Top View Hardware 


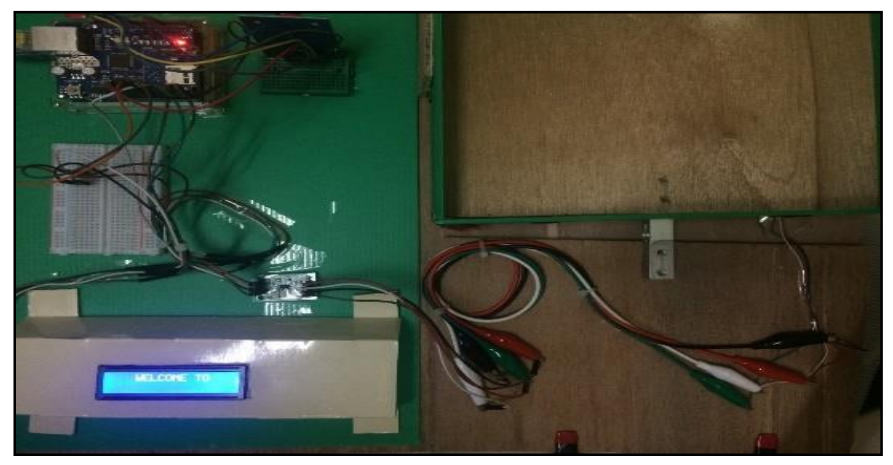

Figure 5. Getting Started - System's Title

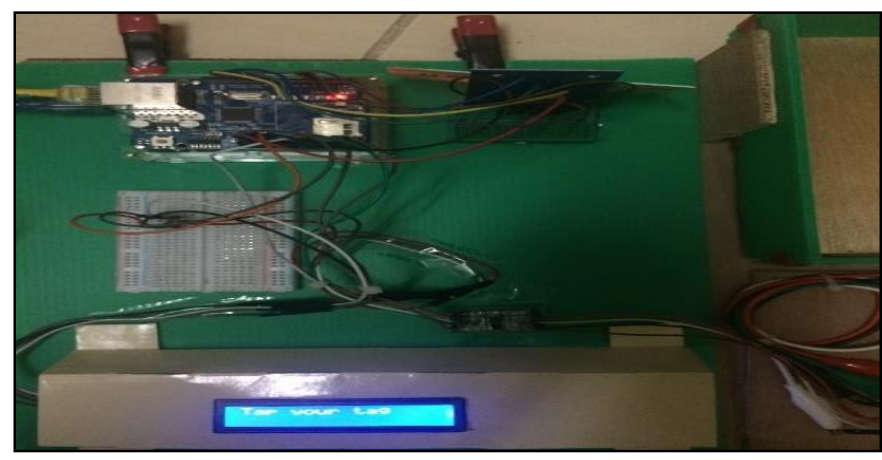

Figure 6. Getting Started - Instructions to User

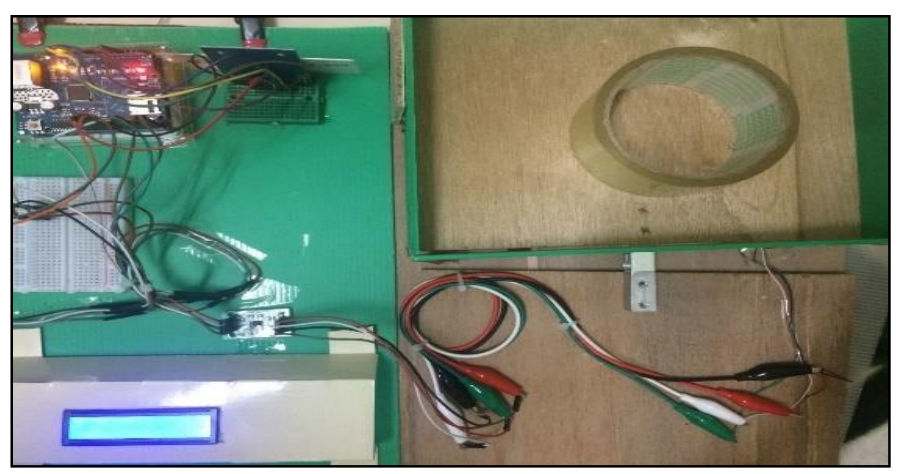

Figure 7. Weighing the recycle waste

This project requires an installation of XAMPP, stands for Cross-Platform (X), Apache (A), MariaDB (M), PHP (P) and Pearl (P) software - a free and open-source cross-platform web server solution stack package developed by Apache Friends. The development of the database is created in phpMyAdmin, a free software tool written in PHP, intended to handle the administration of MySQL over the Web. This database is used to create, insert, update and save all users' information based on their RFID tag. The platform used to upload the program code for Webpage development is a Notepad ++ .

\section{RESULTS AND FINDINGS}

The development of this prototype model is expected to increase the motivation and change the mentality of Malaysian towards recycling activities, hence the introduction of the rebate points as a reward. The system has been tested with 5 different users, hence 5 different RFID tags. The successful integration of hardware and software on this IoT-based system can be seen through the following: the welcoming address, 
instructions to users, total weight of the waste and rebate points have successfully displayed on the LCD, and the same data is also displayed on the Webpage together with an additional users' information as shown in Figure 9.

Figure 8 shows the weight of the recycle waste and the rebate points awarded being displayed on the LCD. There are 5 different items have been used to represent the recycle waste, shown in the figure is a roll of tape. The maximum weight for the load cell to measure is up to $1 \mathrm{~kg}$, weighing more than $1 \mathrm{~kg}$ would result to an inaccurate reading. Since this is a small-scale prototype model, the items chosen to represent the waste are all basically a light weight item. If the load cell is not properly and tightly installed, it will affect the weight measurement, thus contributes to an inaccurate reading.

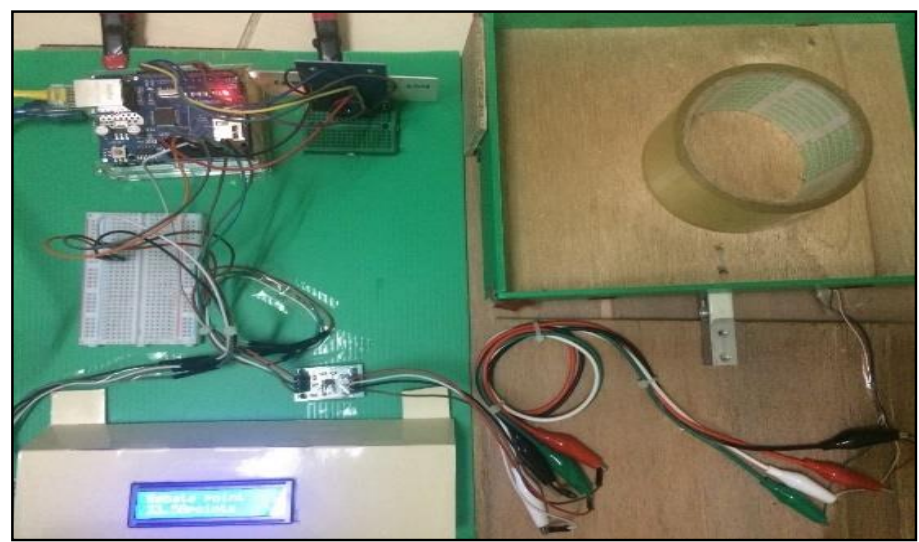

Figure 8. Weight and Rebate Points on LCD

Figure 9 shows the Webpage that displays the same output (weight and rebate points) as on LCD, plus the information details of the users tagged by RFID reader. It is noticed that the information displayed on the Webpage are correct with each RFID tag number. They are corresponding to the right user and right email address. The system is intended for the Waste Management's administrator to monitor the recycling activities done by the users.

All the details of the development of the prototype, installation of the XAMPP Software and the development of the database and the Webpage can be found in [22].

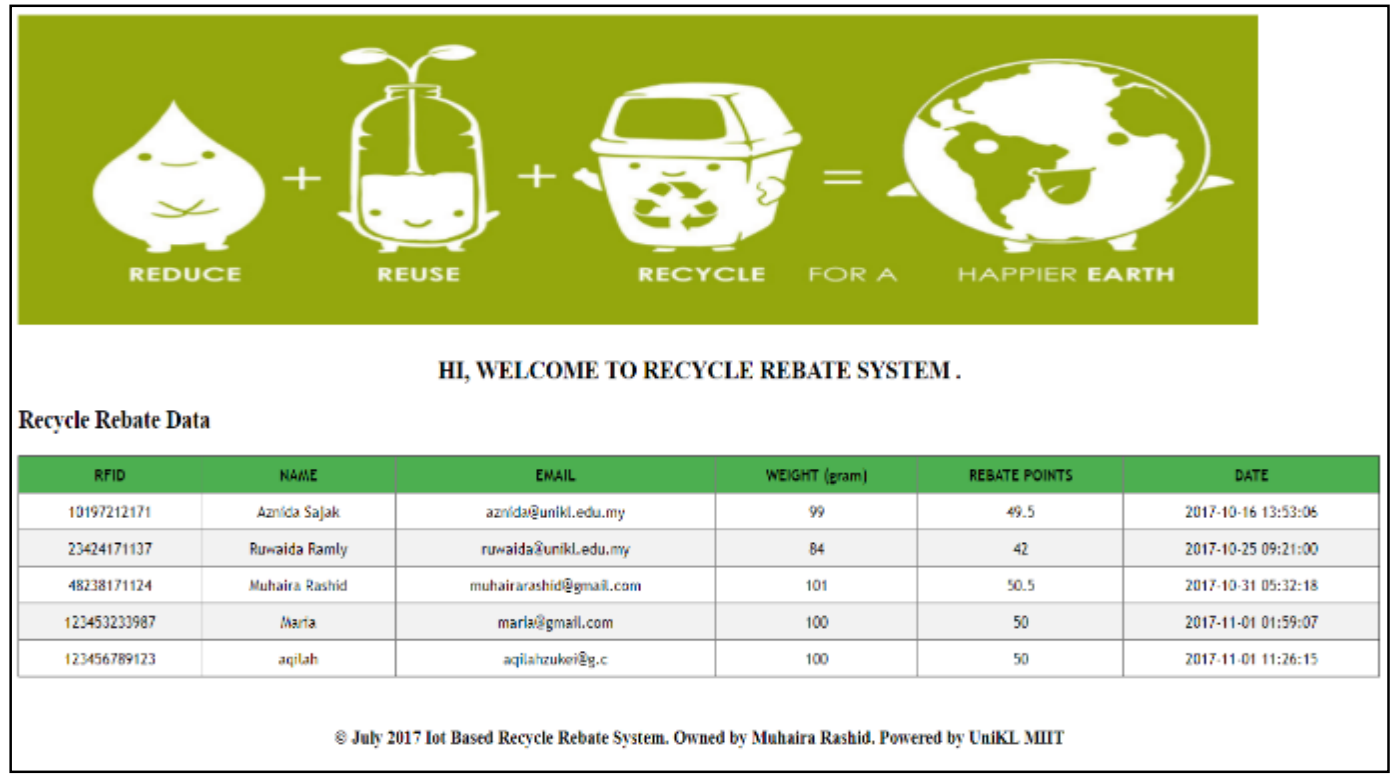

Figure 9. Webpage Interface for Administrator 


\section{CONCLUSIONS}

IoT Recycle Management System is an innovation system where the idea is derived from the green initiatives by Government of Malaysia. The idea to allocate rebate points as a reward to users is derived from the observation to Malaysian's mentality. Malaysians are not committed to recycle their unwanted things for instance papers, plastic bottles and drinking cans because the benefit of recycling is not attractive enough. Currently, they come to the recycling center with their recycle wastes, weight the wastes then the recycling center staff will give some cash that depends on the total weight of recycle waste. However, in return, the cash value is not worthy when compared to the total weight of the recycle wastes. This is the reason why it is difficult to convince Malaysian to recycle. The rebate points can be integrated with the Putrajaya Holdings administration system and Sepang City Council system on paying various taxes where the taxes can be redeemed with the awarded rebate points stored in the database. This will surely be an attractive incentive to encourage Malaysian to recycle.

A mobile application for users or the administrators can also be implemented to make this system more user-friendly. Since the system is used to support Green Technology, it is only fair for the prototype to utilize the energy from the solar panel. Hence, solar panel attached on top of the recycle bins is also a good improvement idea. A centralized monitoring system controlled at the recycling center to monitor the threshold level of the recycle waste might also be implemented to alert the worker at the site to collect the recycle waste.

As a conclusion, this prototype model has a big potential to be implemented in aspiring Green Cities such as Putrajaya and Cyberjaya to support Green City Initiatives in Malaysia.

\section{REFERENCES}

[1] A. Schwartz, Design, Environment, Green Furniture, Recycling, Social Design, https://inhabitat.com/

[2] C. Scott, Architecture, Environment, Water Issues, https://inhabitat.com/

[3] A. Lisa, Design, Environment, Green Furniture, Recycling, Social Design, https://inhabitat.com/

[4] Green City Low Carbon Initiative Putrajaya Holdings, 1st edition, 2012.

[5] S. Patil, et al.,"IoT Based Smart Waste Management System for Smart City,"International Journal of Advanced Research in Computer Science and Software Engineering, vol. 7, no. 4, pp. 407-410, 2017.

[6] A. Imam, et al., "Solid waste management in Abuja, Nigeria", Waste Management,pp. 468-472, 2008.

[7] C.Hicks, et al., "The recycling and disposal of electrical and electronic waste in China-legislative and market responses," Environmental Impact Assessment Review, vol. 25, pp.459-471, 2005.

[8] X.Chi, et al., "Informal electronic waste recycling: A sector review with special focus on China," Waste Management, pp. 731-742, 2011.

[9] O. M. Poulsen, et al., "Collection of domestic waste. Review of occupational health problems and their possible causes," Science of The Total Environment, pp. 1-19, 1995.

[10] X.Chi, et al., "E-waste collection channels and household recycling behaviors in Taizhou of China," Journal of Cleaner Production, vol. 80, pp. 87-95, 2014.

[11] R. Bai, et al., "The practice and challenges of solid waste management in Singapore," Waste Management, pp. $557-567,2002$.

[12] F. T. Seik "Recycling of domestic waste: Early experiences in Singapore," Habitat International, pp. 277-289, 1997.

[13] B. I. Shaikh, et al., “A Review : Multipurpose Garbage Monitoring System Using IoT, ” International Journal on Recent and Innovation Trends in Computing and Communication, vol.5, no. 2, pp. 252-255, 2017.

[14] B. Singh and M. Kaur,"Smart Dustbins for Smart Cities," International Journal of Computer Science and Information Technologies, vol.7, no. 2, (2016) pp. 610-611, 2016.

[15] I. Hong, et al., "IoT-Based Smart Garbage System for Efficient Food Waste Management", The Scientific World Journal, vol. 2014, 2014.

[16] L.Zhang, et al., "Knowledge Management Application of Internet of Things in Construction Waste Logistics with RFID Technology," International Journal of Computing Science and Communication Technologies, vol. 5, no. 1, pp. 760-767, 2012.

[17] N. S. Kodi, et al., "Food Waste Management System using Load Cell," International Journal of Science \& Technology, vol. 8, no.1, 2018.

[18] K. Lata1, et al., "IoT Based Smart Waste Management System Using Wireless Sensor Network and Embedded Linux Board," International Journal of Current Trends in Engineering \& Research, vol. 2, no. 7, pp. 210-214, 2016.

[19] N. A. Sharaaf, "Easy Clean-A Smart Solution for Garbage Finding and Collecting," International Journal of Computer Applications, vol. 169, no.3, 2017.

[20] A. Lozano, et al., "Smart Waste Collection System with Low Consumption LoRaWAN Nodes and Route Optimization," Sensors, vol.18, issue 5, 2018.

[21] S. Mdukaza, et al., "Analysis of IoT-Enabled Solutions in Smart Waste Management," The 44th Annual Conference of the IEEE Industrial Electronics Society, 2018.

[22] Muhaira R, IoT Based Recycle Rebate System, Universiti Kuala Lumpur, 2017. 


\section{BIOGRAPHIES OF AUTHORS}
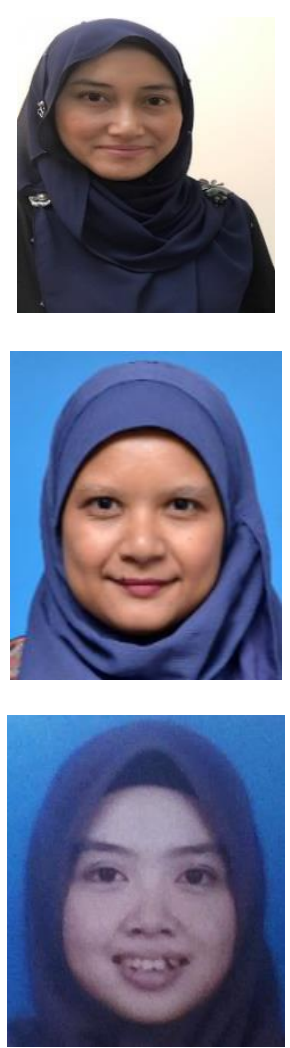

Ruwaida Ramly received the MEng. degree in Communication \& Computer from the National University of Malaysia (UKM) in 2012. Has been in electronics manufacturing industry and with 14 years of experience in tertiary education, she is actively involved in students' project development and her current research interest include Sensor Techology in IoT.

Aznida Abu Bakar Sajak received the M.Sc.(Eng.) degree in microelectronic systems \& telecommunications from the University of Liverpool, Liverpool, U.K., in 2005. Holds a Ph.D. degree in Electrical Engineering and Electronics at the University of Liverpool, Liverpool, UK. From 2006 to 2012, she was with Digi Telecommunication, Telenor Norway affiliates as a core network transmission engineer. Her current research interests include $\mathrm{THz}$ antenna design and analysis.

Muhaira Rashid received the degree in computer engineering from the University of Kuala Lumpur in 2018. Currently working as back end system developer for PetBacker application in Vision Technology Consulting's project. 